\title{
Avaliação clínica e hematológica de equinos submetidos ao modelo de laminite por oligofructose, tratados ou não com um agente antagonista de receptores CXCR1/2
}

\author{
Leonardo R. de Lima², Heloisa M.F. Mendes², Jessica F. Magalhães², Ludmilla C. Markowicz², \\ Carolina B. Cavalcanti ${ }^{2}$, Fabíola O. Paes Leme ${ }^{2}$, Mauro M. Teixeira ${ }^{3}$ e Rafael R. Faleiros ${ }^{2 *}$
}

\begin{abstract}
Lima L.R., Mendes H.M.F., Magalhães J.F., Markowicz L.C., Cavalcanti C.B., Paes Leme F.O., Teixeira M.M. \& Faleiros R.R. 2013. [Clinical and hematological evaluation of horses subjected to oligofructose-induced laminitis treated or not with a CXCR1/2 antagonist.] Avaliação clínica e hematológica de equinos submetidos ao modelo de laminite por oligofructose, tratados ou não com um agente antagonista de receptores CXCR1/2. Pesquisa Veterinária Brasileira 33(8):992-998. Escola de Veterinária, Universidade Federal de Minas Gerais, Avenida Antônio Carlos 6627, Pampulha, Belo Horizonte, MG 30123-970, Brazil. E-mail: faleirosufmg@gmail.com

Leucocytes recruitment to tissues is an essential part of the innate immune response and an unregulated process can result in tissue damage. Thus, leucocytes infiltration has been implicated in the pathogenesis of acute laminitis. The objectives of this stud were to determine the effect of an antagonist for CXCR1/2, a chemokine receptor for neutrophils attraction on clinical signs and hematological parameters in horses given oligofructose to induce laminitis. Twelve horses were given oligofructose $(10 \mathrm{~g} / \mathrm{kg}$ bw PO) in time 0 and divided into two groups: one treated (30 mg/kg bw. ICXCR1/2 IV, times 6, 12, 18 e $24 \mathrm{~h}$ ) and the other not treated. Cardiac and respiratory frequency, rectal temperature, mucous membrane colour, digital pulse, hoof sensitivity and Obel's grade of lameness were recorded. Values for RBC, WBC and blood glucose, BUN, creatinin, ALT, AST, alkaline phosphatase, GGT, total bilirubin and serum protein concentrations were measured on times $0,6,12$, $18,24,36,48,60$ e $72 \mathrm{~h}$. All the horses given oligofructose developed signs of endotoxemia like diarrhea, fever and leukocytosis and laminitis. Also, CXCR1/2 antagonist treatment did not cause any adverse effects. However, this substance when injected intravenously $(30 \mathrm{mg} / \mathrm{kg}) 6 / 6$ hours in 4 applications, did not ameliorate clinical and hematological signs of endotoxemia.
\end{abstract}

INDEX TERMS: Horse, laminitis, neutrophils, chemokine.

RESUMO.- O recrutamento de leucócitos aos tecidos é uma parte essencial da resposta imune inata e esse processo de forma desregulada pode resultar em lesões aos tecidos. Assim, a infiltração de leucócitos tem sido implicada na patogênese de laminite aguda em equinos. Os objetivos

\footnotetext{
${ }^{1}$ Recebido em 2 de janeiro de 2013.

Aceito para publicação em 16 de julho de 2013.

${ }^{2}$ Escola de Veterinária, Universidade Federal de Minas Gerais (UFMG), Av. Antônio Carlos 6627, Belo Horizonte, MG 30123-970, Brasil.

${ }^{3}$ Instituto de Ciências Biológicas (ICB, Bloco K4), Universidade Federal de Minas Gerais, Avenida Antônio Carlos 6627, Caixa Postal 486, Pampulha, Belo Horizonte, MG 31270-901. *Autor para correspondência: faleirosufmg@gmail.com
}

dessa pesquisa foram verificar a ação da ICXCR1/2 sobre os sinais clínicos e parâmetros hematológicos de cavalos com laminite induzida por oligofrutose. Doze equinos receberam oligofrutose $(10 \mathrm{~g} / \mathrm{kg}$ de peso vivo PO) no tempo 0 e foram divididos em 2 grupos: tratados $(30 \mathrm{mg} / \mathrm{kg}$ p.v. ICXCR1/2 IV, nos tempos 6, 12, 18 e 24 h) e não tratados. As frequências cardíaca e respiratória, temperatura retal, coloração de membranas mucosas, presença e intensidade de pulso digital, sensibilidade ao exame com pinça de casco e grau de claudicação segundo Obel, bem como parâmetros hematológicos e bioquímicos (hemograma e as concentrações sanguíneas de glicose, uréia, creatinina, ALT, AST, FA, GGT, bilirrubina total e proteína total) foram aferidos nos tempos $0,6,12,18,24,36,48,60$ e 72 horas . 0 modelo 
usando oligofructose foi adequado para induzir sinais de laminite e de sinais de endotoxemia, como diarreia, febre e leucocitose em cavalos sem raça definida de origem nacional. Também, não foram observadas quaisquer reações adversas clínicas ou hematológicas relacionadas ao uso intravenoso do antagonista de CXCR1/2, contudo essa substância, quando administrada na dose de $30 \mathrm{mg} / \mathrm{kg}$ de peso vivo, 4 vezes ao dia, por 4 aplicações, não foi capaz de prevenir os sinais clínicos e as alterações hematológicas causadas pela administração de oligofructose nos equinos deste estudo.

TERMOS DE INDEXAÇÃO: Laminite, neutrofilos, quimiocinas, equidae.

\section{INTRODUÇÃO}

0 recrutamento de neutrófilos ao tecido inflamado é uma parte essencial da resposta imune inata. Além disso, a liberação de mediadores químicos a partir de um foco inflamatório é capaz de promover a ativação e a infiltração de leucócitos em órgãos distantes da lesão original (Faleiros et al. 2008). Dessa maneira, leucócitos desempenham um papel central na injúria tecidual em várias doenças e estão intimamente relacionados à falência orgânica durante a Síndrome da Resposta Inflamatória Sistêmica (SIRS) (Belknap et al. 2007).

A ativação sistêmica de leucócitos e a migração dessas células para o interstício têm sido demonstradas nas lâminas do casco e em outros órgãos de cavalos durante a fase de desenvolvimento da laminite (Black et al. 2006, Faleiros et al. 2008). Assim, inflamação sistêmica semelhante à SIRS, prévia ao desenvolvimento da falência de órgãos, parece preceder a falência lamelar em cavalos (Hurley et al. 2006, Belknap et al. 2007, Loftus et al. 2007a, 2007b, Stewart et al. 2009).

CXCL8 ou Interleucina 8 (IL-8) é um membro da subfamília CXC das quimiocinas e é uma potente substância atrativa para neutrófilos. Sua ação é mediada por receptores CXCR1 e CXCR2 acoplados a proteína G (GPCRs), que têm alta afinidade por quimiocinas glutamina-leucina-arginina positivas (Mukaida 2003, Kim et al. 2011). IL-8 tem sido detectada em vários tecidos humanos acometidos por condições inflamatórias como psoríase (Giustizieri et al. 2001), asma e doença pulmonar obstrutiva crônica (Woodman et al. 2006), todas condições associadas com severa infiltração neutrofílica. De forma semelhante, no cavalo, desafios antigênicos levam ao aumento da expressão de IL-8 e seu respectivo mRNA nos pulmões de animais acometidos por doença pulmonar crônica e obstrução recorrente de vias aéreas, condições também associadas a forte infiltração neutrofílica (Franchini et al. 2000, Ainsworth et al. 2006). IL-8 também tem sido implicada na patogênese da endotoxemia equina. Endotoxinas foram capazes de aumentar a expressão de IL-8 nos neutrófilos in vitro (Neuder et al. 2009 ) e no sangue quando injetadas sistemicamente (Nieto et al. 2009). Além disso, o aumento da expressão de citocinas pro-inflamatórias (IL-1, IL-6, IL-8), no estágio de desenvolvimento da laminite, indica que a presença de quimiocinas atrativas de leucócitos (principalmente IL-8) pode desempenhar importante papel na migração leucoci- tária nos eventos iniciais da laminite (Belknap et al. 2007, Faleiros et al. 2009a, 2011b).

Dessa forma, IL-8 é uma molécula chave para a migração e ativação de neutrófilos em órgãos humanos e de equinos danificados pela SIRS. O bloqueio farmacológico seletivo de IL-8 representa um promissor horizonte no controle das lesões de origem inflamatória com potencial para o tratamento e prevenção da laminite equina (Bizzarri et al. 2006, Coelho et al. 2008). 0 antagonista de CXCR1/CXCR2 usado nesse experimento (ICXCR1/2) é um antagonista alostérico não competitivo, inibindo o padrão de sinalização intracelular sem afetar a capacidade de ligação do receptor. Assim, ICXCR1/2 potencialmente inibe uma grande variedade de atividades biológicas induzidas por IL-8 (Souza et al.2004, Bizzarri et al. 2006, Gorio et al. 2007, Zarbock et al. 2008, Marsh \& Flemming 2011). Apesar das recentes evidências da participação de leucócitos na origem da laminite (Fontaine et al. 2001, Belknap et al. 2007, Faleiros et al. 2009a, 2009b, 2011, Lunn \& Hurley 2009) que demonstram potencial terapêutico do ICXCR1/2 da migração de neutrófilos, nenhum estudo com essa droga havia sido conduzido na espécie equina. Assim, os objetivos dessa pesquisa foram verificar a ação da ICXCR1/2 sobre os sinais clínicos e parâmetros hematológicos de cavalos com laminite induzida por oligofrutose. Adicionalmente, verificou-se a a tolerância de equinos à aplicação de ICXCR1/2 pela via intravenosa.

\section{MATERIAL E MÉTODOS}

O experimento foi aprovado pelo Comitê de ética sobre experimentação animal da UFMG (CETEA/UFMG 225/2009). Foram utilizados doze equinos sem raça definida (quatro machos e oito fêmeas, idade média de $7 \pm 3,5$ anos, pesando $305 \pm 35 \mathrm{~kg}$ ), sem histórico prévio de claudicação relacionada aos cascos e previamente adaptados por 2 semanas ao confinamento em baia e a uma dieta exclusiva à base de feno de gramínea (Cynodum sp.). Os animais foram divididos aleatoriamente em dois grupos, controle $(n=6)$ e tratado $(n=6)$. No tempo considerado zero (T0), todos os animais receberam $10 \mathrm{~g} / \mathrm{kg}$ de peso vivo de oligofrutose (Raftilose P95) diluídos em 3 litros de água, via sonda naso-gástrica (Van Eps \& Pollit, 2006). Nos tempos 6, 12, 18 e 24 horas, os animais do grupo tratado receberam por infusão intravenosa durante $10 \mathrm{mi}-$ nutos $30 \mathrm{mg} / \mathrm{kg}$ (Souza et al. 2004) de peso vivo de ICXCR1/2 base diluídos em salina estéril 0,9\% e filtrados em filtro bacteriológico de $0,22 \mu \mathrm{m}$ (Biofil syringe filter, Jet Biofil, www.jetbiofil.com ).

Nos tempos $0,12,36$ e 72 horas, 3 biópsias de cada casco foram coletadas sequencialmente no membro posterior esquerdo (T0), posterior direito (T12), anterior direito (T36) e anterior esquerdo (T72). As biópsias tiveram como objetivo um estudo paralelo sobre histologia e biologia molecular.

Os animais foram monitorados clinicamente nos tempos 0,6 , $12,18,24,36,48,60$ e 72 horas, seguidos imediatamente pela coleta de sangue. Os seguintes parâmetros foram avaliados: frequência cardíaca, frequência respiratória, temperatura retal, coloração de membranas mucosas, presença e intensidade de pulso digital, presença e intensidade dos sons intestinais, sensibilidade ao exame com pinça de casco e grau de claudicação segundo Obel.

Amostras de sangue foram coletadas pela punção da veia jugular, acondicionadas em 3 tubos distintos (sem anticoagulante, com ácido etileno-diamino-tetracético - EDTA e com fluoreto) e refrigeradas imediatamente até a realização de hemograma e separação de soro e plasma. As amostras de sangue sem anticoa- 
gulante foram centrifugadas por $5 \mathrm{~min}$, a $3000 \mathrm{G}$ até completar a separação da fração líquida (soro) que foi armazenada em freezer a $-18^{\circ} \mathrm{C}$. As amostras congeladas foram submetidas às análises bioquímicas em no máximo sete dias.

As seguintes análises hematológicas e bioquímicas foram realizadas: hemograma, glicose, uréia, creatinina, lactato, CK, ALT, AST, FA, GGT, bilirrubina total e proteína total. Para determinação do volume globular (VG) foi utilizada a técnica de micro-hematócrito com centrifugação durante $10 \mathrm{~min}$ a $10000 \mathrm{rpm}$. A concentração de proteína plasmática total foi determinada por refratometria. A contagem das células sanguíneas foi realizada em aparelho automático através da técnica de impedância elétrica (ABACUS JUNIOR VET). A contagem diferencial dos leucócitos foi realizada em esfregaços sanguíneos corados com panótico, avaliando-se 100 células. Para mensuração da glicemia foram utilizadas amostras de plasma em fluoreto, obtidas após centrifugação pelo método anteriormente descrito. Para todas as variáveis bioquímicas foram utilizados kits comerciais da marca Synermed ${ }^{\circledR}$. Todas as análises bioquímicas foram realizadas em aparelho espectrofotométrico automático (Cobas-Mira Plus).

Os dados foram submetidos à análise estatística pelo programa Prism 5 for Windows (version 5.00 (Trial), utilizando-se o teste de normalidade de Kolmogorov-Smirnov e análise de variância (ANOVA), seguido do teste de Student Newman Keuls. Para dados não paramétricos ou sem distribuição normal utilizou-se o teste de Friedman para comparação de tempos dentro de grupos e o teste de Wilcoxon para comparação de grupos em cada tempo. Para todos os testes, considerou-se um nível de significância igual a $\mathrm{P}<0,05$.

\section{RESULTADOS}

Nenhuma das análises estatísticas demonstrou efeito significativo do tratamento, contudo em várias delas detectou-se efeito do tempo independente do grupo. Desta forma optou-se por analisar os grupos (tratados e não tratados) em conjunto. Foi observado aumento da frequência cardíaca nos tempos 36 e 48 horas (Fig.1). Entretanto não foi observada alteração da frequência respiratória em nenhum dos dois grupos. Com 24 e 36 horas, houve elevação da temperatura retal (Fig.2). Diarreia foi um sinal clínico presente em todos os animais e teve início às 12 horas e terminando às 48 horas. A maioria dos animais estava com diarreia às

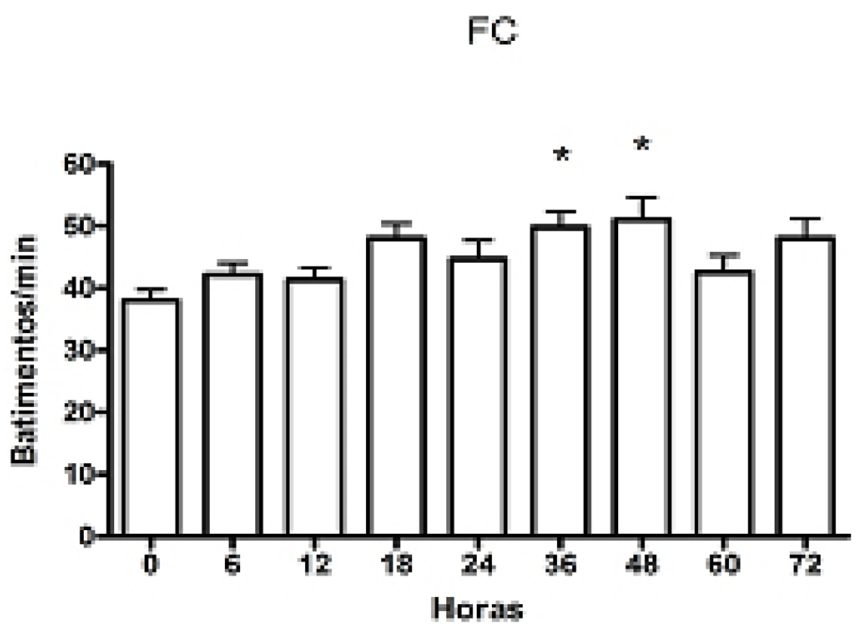

Fig.1. Médias e erros-padrão da frequência cardíaca em equinos com laminite induzida por oligofrutose $(10 \mathrm{~g} / \mathrm{kg})$. * Difere do tempo 0 considerando-se $\mathrm{P}<0,05$.
Temperatura Retal

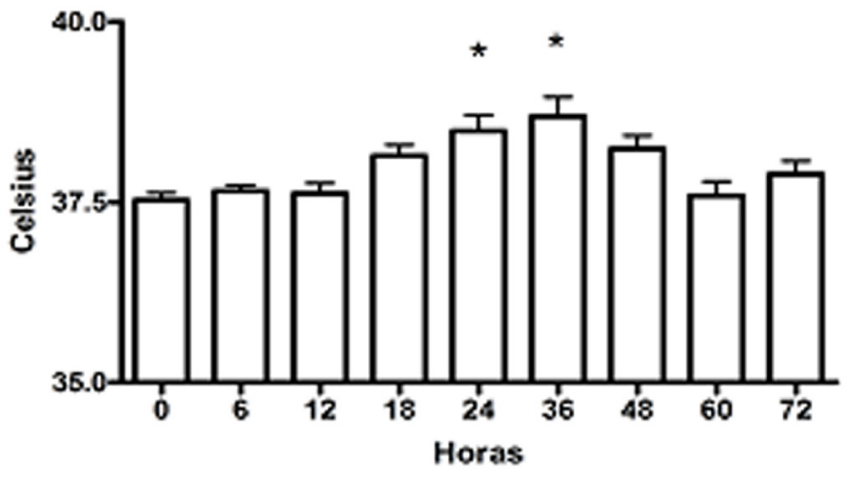

Fig.2. Médias e erros-padrão da temperatura retal em equinos com laminite induzida por oligofrutose $(10 \mathrm{~g} / \mathrm{kg}) .{ }^{*}$ Difere do tempo 0 considerando-se $\mathrm{P}<0,05$.

\section{Grau de Obel}

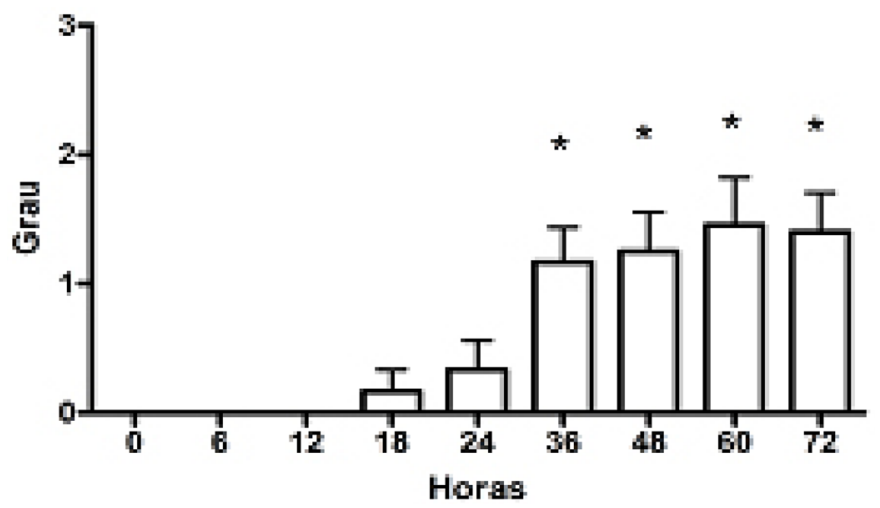

Fig.3. Médias e erros-padrão do grau de claudicação segundo Obel em equinos com laminite induzida por oligofrutose $(10 \mathrm{~g} / \mathrm{kg})$.

* Difere do tempo 0 considerando-se $\mathrm{P}<0,05$.

\section{Leucócitos totails}

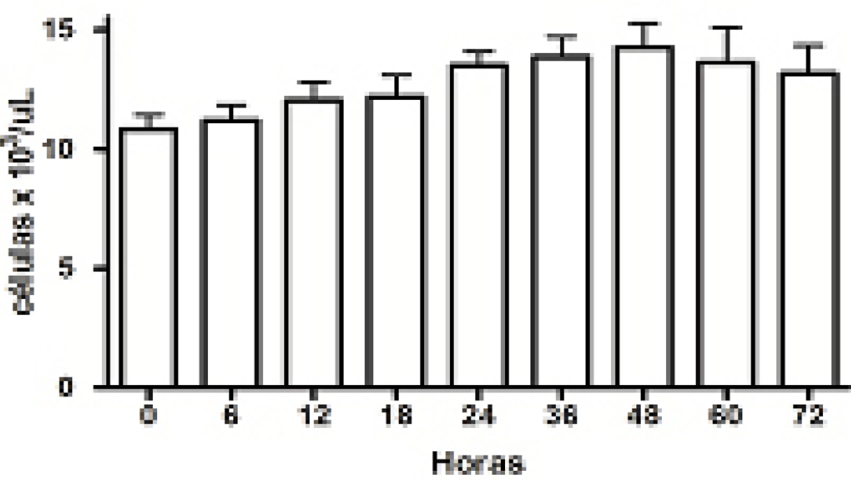

Fig.4. Médias e erros-padrão da leucometria em equinos com laminite induzida por oligofrutose $(10 \mathrm{~g} / \mathrm{kg}) .{ }^{*}$ Difere do tempo 0 considerando-se $\mathrm{P}<0,05$.

$24(10 / 12)$ e às 36 horas $(9 / 12)$. Congestão de mucosa foi presente em todos os animais entre 24 e 48 horas e metade manteve a congestão até o fim do experimento. A maioria dos animais apresentou motilidade intestinal normal durante todo o experimento, com aumento coincidindo com 
o período de diarreia. Contudo, dois animais apresentaram hipomotilidade entre 36 e 48 horas.

Com relação à sensibilidade do casco ao exame de pinça, nenhum animal apresentou sinal positivo. A presença de pulso digital apareceu entre 18 e 24 horas e permaneceu até o fim do experimento. A partir de 36 horas foi observa-

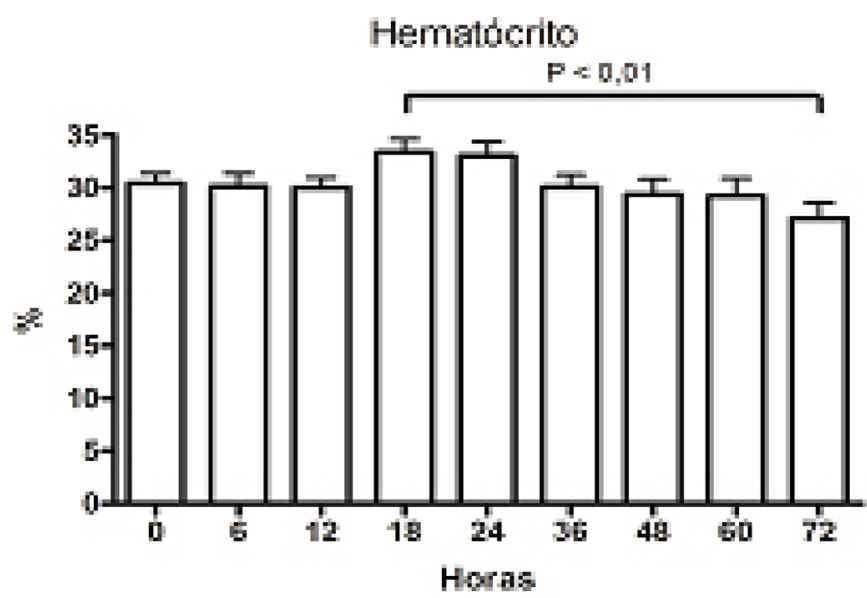

Fig.5. Médias e erros-padrão do hematócrito em equinos com laminite induzida por oligofrutose $(10 \mathrm{~g} / \mathrm{kg}) *$ Difere do tempo 0 considerando-se $\mathrm{P}<0,05$.

Hemácias

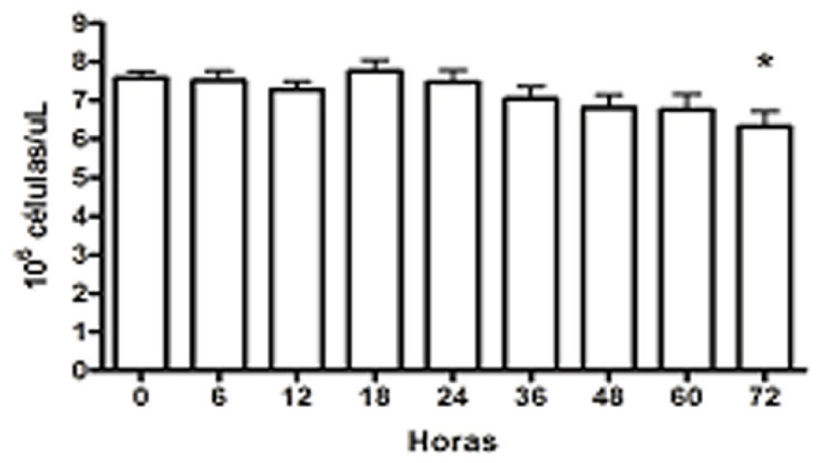

Glic ose

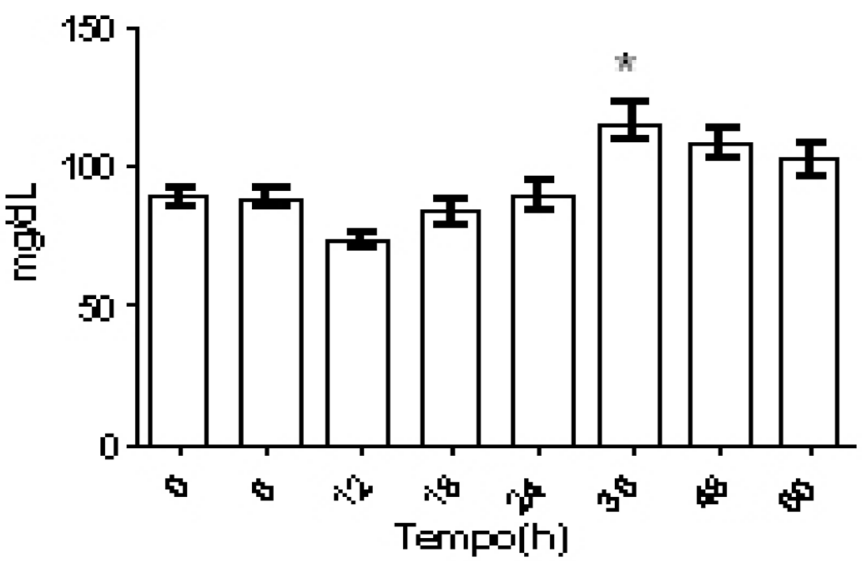

Fig.7. Médias e erros-padrão da concentração sanguínea de glicose em equinos com laminite induzida por oligofrutose $(10 \mathrm{~g} /$ $\mathrm{kg})$. * Difere do tempo 0 considerando-se $\mathrm{P}<0,05$.

do aumento do escore de claudicação segundo Obel que se manteve até o fim do experimento (Fig.3).

As principais alterações hematológicas observadas foram o aumento da contagem leucocitária 48 horas após a indução (Fig.4), diminuição na contagem de hemácias e nos

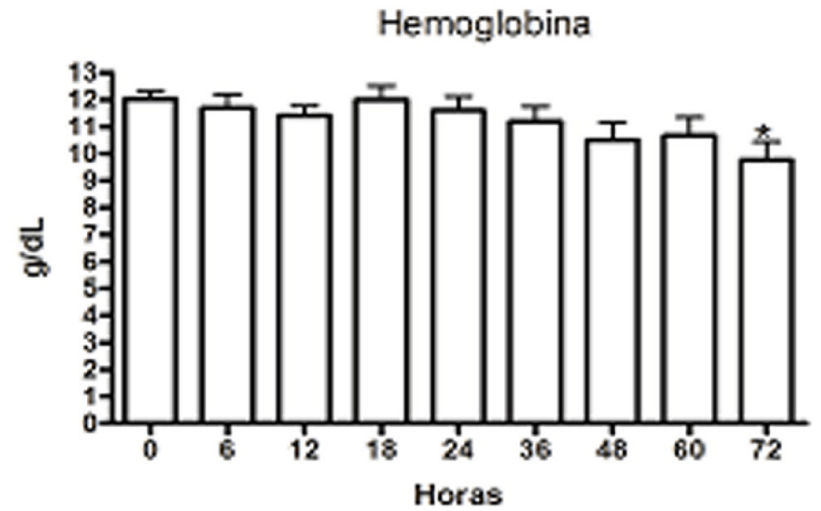

Fig.6. Médias e erros-padrão da contagem de hemácias totais e da concentração de hemoglobina em equinos com laminite induzida por oligofrutose $(10 \mathrm{~g} / \mathrm{kg})$. * Difere do tempo 0 considerando-se $\mathrm{P}<0,05$.

\section{Creatinina}

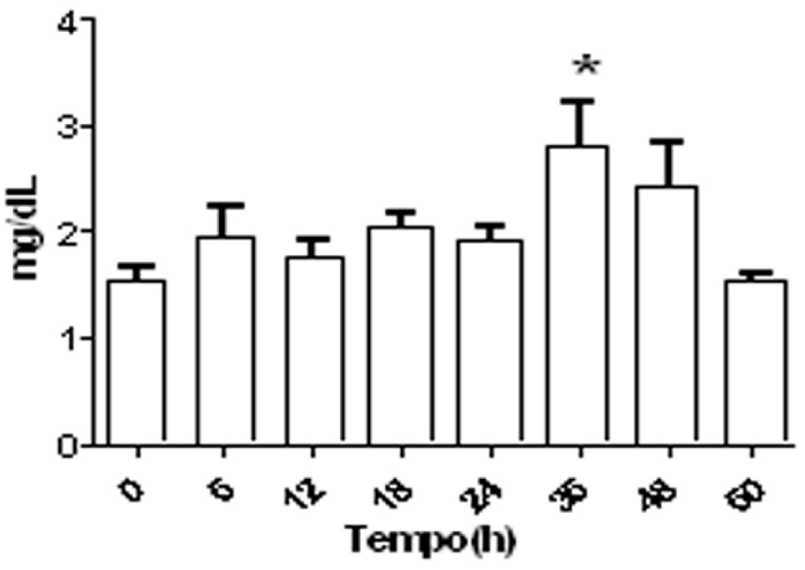

urèa

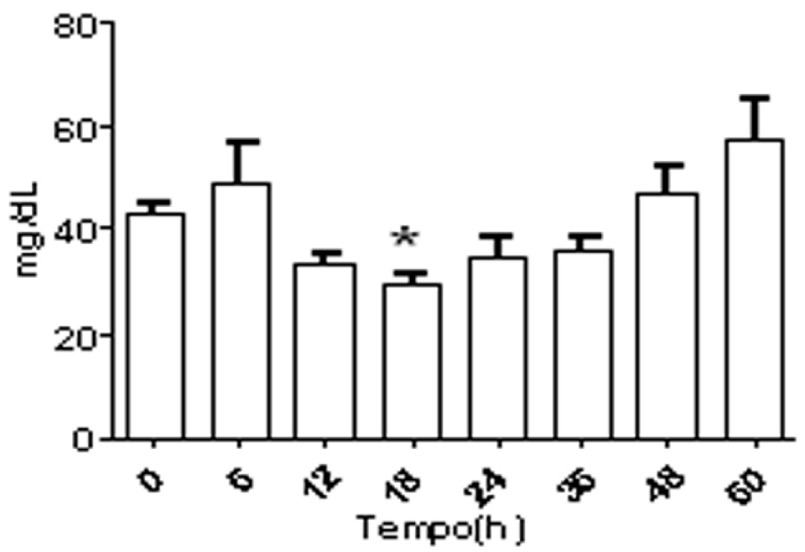

Fig.8. Médias e erros-padrão da concentração sanguínea de creatinina e uréia em equinos com laminite induzida por oligofrutose (10g/ kg). * Difere do tempo 0 considerando-se $\mathrm{P}<0,05$. 


\section{Bilirr Ubina}

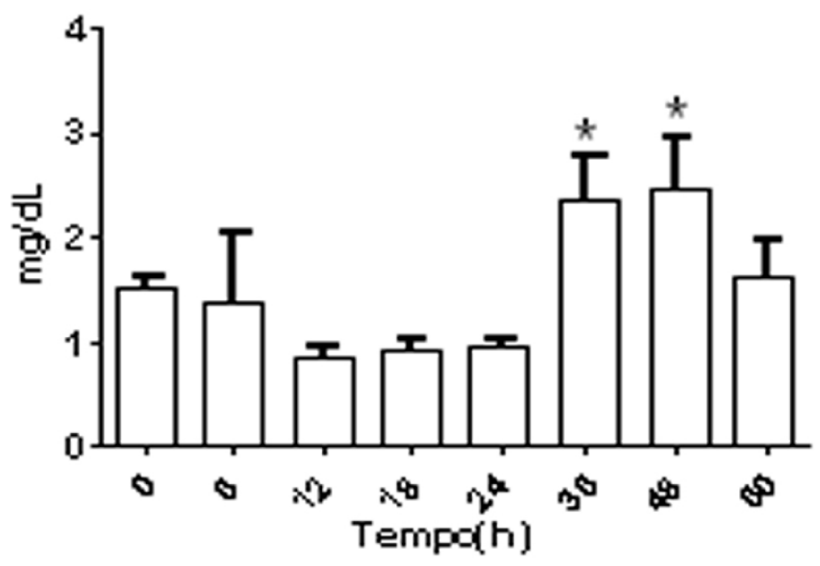

ALT(TGP)

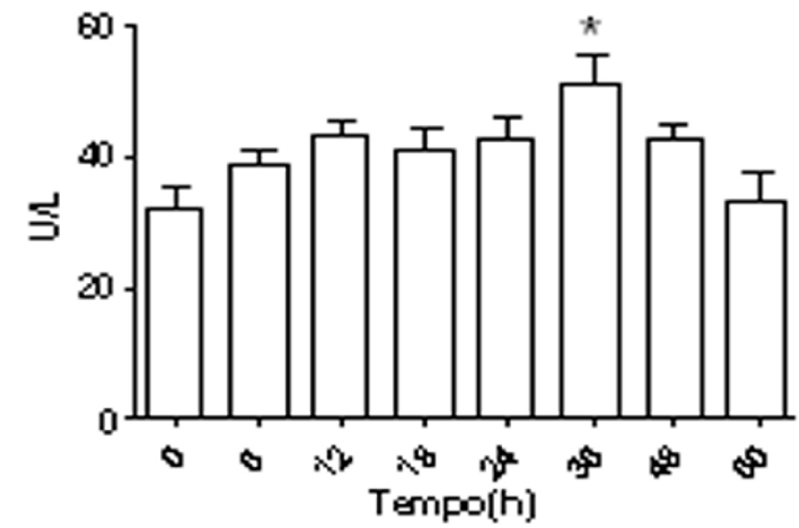

Fig.9. Médias e erros-padrão da concentração sanguínea de ALT e bilirrubina total em equinos com laminite induzida por oligofrutose $(10 \mathrm{~g} / \mathrm{kg}) .{ }^{*}$ Difere do tempo 0 considerando-se $\mathrm{P}<0,05$.

níveis de hemoglobina no tempo 72 horas (Fig.6), elevação no hematócrito no tempo 18 horas e diminuição ao final do experimento (72 horas) (Fig.5), mas sem alterações nas contagens de plaquetas.

Não houve alterações significativas nas variáveis proteínas totais. Uma elevação significativa na glicemia ocorreu no tempo 36 horas $(\mathrm{p}<0.001)$ quando se consideram todos os indivíduos submetidos ao protocolo de indução de laminite (Fig.7). Também houve aumento significativo da creatinina sérica no tempo 36 horas. Por outro lado, houve uma redução da uréia no tempo 18 horas com recuperação dos níveis anteriores no tempo 60 horas (Fig 8).

Novamente, no tempo 36 horas houve elevação nos níveis de ALT e bilirrubina total (Fig 9) com persistência da hiperbilirrubinemia no tempo 48 horas. (Fig.9). Nas outras variáveis bioquímicas (lactato, albumina, GGT, FA, AST, CK) não houve alterações significativas entre os grupos e nem ao longo do tempo.

\section{DISCUSSÃO}

Todos os cavalos utilizados nesse estudo desenvolveram sinais compatíveis com endotoxemia (febre, leucocitose, diarreia e mucosas congestas) e laminite, (aumento do pulso digital e claudicação) confirmando a validade do modelo experimental. De fato, a dose de $10 \mathrm{~g} / \mathrm{kg}$ de peso vivo de oligofrutose (Raftlose P95) usada nesse experimento tem sido preconizada como padrão para indução de laminite em equinos (Van Eps \& Pollitt 2006, Visser \& Pollitt 2011, Visser \& Pollitt 2012, Van Eps et al. 2012). Todavia, a utilização da ICXCR1/2 na dose de $30 \mathrm{mg} / \mathrm{kg}$ administrados a cada 6 horas por 4 aplicações não foi capaz de impedir o desenvolvimento dos sinais de endotoxemia e laminite.

A presença de pulso evidente nas artérias digitais a partir de 18 horas e de sinais de claudicação a partir de 36 horas da indução com oligofrutose ocorreram de forma semelhante ao observado no trabalho de Van Eps \& Pollitt (2006). Contudo, é importante ressaltar que o grau de claudicação visto no presente estudo, em equinos de ambos os grupos (Fig.3), foi aquém do observado em outros estudos utilizando a mesma dose de oligofructose. Enquan- to os animais daqui desenvolveram graus de Obel entre 1 e 2 nos cascos torácicos, estudos prévios relataram graus de 2 a 3 nesses membros usando o mesmo modelo (Van Eps \& Pollitt 2006). Especula-se sobre a influência do peso dos animais, uma vez que no estudo original se utilizaram animais trotadores americanos (van Eps \& Pollitt, 2006). Embora não mencionado pelos autores, o peso médio dessa raça é em torno de $450 \mathrm{Kg}$, enquanto que o peso médio dos animais em nosso experimento foi de apenas $305 \mathrm{~kg}$. Segundo os autores que desenvolveram o modelo da oligofrutose, apesar dos resultados serem mais previsíveis que a ingestão de grandes doses de amido, animais mais leves podem ser refratários ao desenvolvimento de sinais clínicos (Van Eps, comunicação pessoal).

Outras considerações plausíveis para a menor manifestação clínica de dor seriam as características dos animais e o uso de biópsias de casco no presente estudo. A primeira refere-se ao fato dos animais brasileiros poderem apresentar um fenótipo metabólico diferente da outra raça internacional previamente estudada e dessa forma reagirem de forma mais branda a um desafio semelhante com oligofrutose. Quanto às biópsias, foram realizadas três em cada casco, resultando em significante perda sanguínea, que poderia trazer efeito anti-inflamatório benéfico ao reduzir a pressão compartimental do casco e reduzir a concentração de substâncias potencialmente deletérias às lâminas como citocinas (Belknap et al. 2007) e células (Faleiros et al. 2012) inflamatórias, além de possíveis fatores microbianos ativadores de metaloproteinases (Pollitt 2007) e aminas vasoativas (Botteon et al. 2008).

Apesar da presença de pulso e claudicação, não se observaram, em qualquer momento, sinais de dor na sola por meio do uso da pinça de casco. A fase de desenvolvimento da laminite é considerada como o período entre o aparecimento do fator desencadeante e o início da claudicação. A fase aguda é o período desde o aparecimento da claudicação até 72 horas ou até o início da rotação da falange distal. Na fase de desenvolvimento e na fase aguda da laminite contempladas nesse experimento, as lesões se concentram na porção submural do estojo córneo, não havendo 
comprometimento do cório solear. Assim, devido à natureza mais maleável da sola em comparação com a muralha, a pressão exercida pela pinça de casco tende a deformar somente a sola, poupando as áreas comprometidas pelas lesões iniciais da laminite aguda. Dessa forma, a sensibilidade da sola ao exame com pinça de casco ocorre somente quando há isquemia provocada pelo deslocamento palmar da falange distal e pode dessa forma estar ausente nas fases iniciais da laminite (Pollitt 2007).

Um achado consistente observado no presente estudo foi a presença de diarreia em todos os animais, se iniciando às 12 horas e predominando entre 24 e 48 horas pós-indução. A duração de até 48 horas foi inclusive maior que a observada no grupo de animais recebendo a mesma quantidade de oligofrutose (10g/kg) (Van Eps \& Pollitt 2006). 0 influxo osmótico de água para o lume intestinal associado ao desequilíbrio da microbiota pela alteração do pH, ambos provocados pela chegada abrupta de grandes quantidades de oligossacarídeos ao ceco e cólon, foi a causa provável da diarreia (Moore et al. 1981, Clarke et al. 1982, Milinovich et al. 2006, Milinovich et al. 2010). 0 aumento da motilidade intestinal no mesmo período da diarreia indica o aumento da taxa de passagem da ingesta e possivelmente propiciou o aparecimento de espasmos responsáveis pelo desconforto abdominal. Nesse sentido, o aumento da frequência cardíaca coincidiu com o período de diarreia, podendo ser causada pelo desconforto.

Todavia, o aumento da temperatura no período precedente à diarreia também demonstra a presença de endotoxemia (Van Eps \& Pollitt 2006). As lesões da mucosa intestinal pelos produtos ácidos da fermentação da oligofrutose permitem a absorção de endotoxinas que estimulam a liberação de citocinas inflamatórias que promovem febre, congestão de mucosas e taquicardia (Milinovich et al. 2006, Belknap 2010), como as observadas no presente estudo.

As alterações em variáveis sanguíneas também foram condizentes com a diarreia associada à absorção de toxinas bacterianas e sinais de laminite. 0 sequestro de grande quantidade de fluidos no lume intestinal e o aumento do tônus simpático, devido à dor promovida pela laminite, podem explicar o pico nos valores de hematócrito verificado entre 18 e 36 horas. Ao final do período experimental observou-se queda no hematócrito e na concentração de proteínas totais abaixo de valores basais, fato possivelmente relacionado à fragilidade capilar característica da endotoxemia ou mesmo a um possível efeito da perda de sangue promovida pela coleta de biópsia em três pontos de cada casco, conforme discutido anteriormente.

0 aparecimento de leucocitose no tempo 48 horas se justifica pela endotoxemia. Embora os animais desenvolvessem sinais sistêmicos compatíveis com SIRS (febre, taquicardia e mucosas congestas), uma esperada leucopenia inicial não foi observada. Em geral, sinais graves de SIRS cursam com leucopenia em várias situações clínicas assim como na laminite induzida pelo fornecimento de extrato de nogueira preta (Juglans nigra). Contudo, leucopenia não tem sido observada em cavalos submetidos à sobrecarga com carboidratos (Van Eps \& Pollitt 2006, Faleiros et al. 2011a). Segundo Belknap (2010), a diferença entre os dois modelos é que o extrato de nogueira preta promove uma ativação intensa e fugaz dos leucócitos, que migram rapidamente para os tecidos promovendo leucopenia. Já no modelo de oligofrutose a absorção de toxinas bacterianas ocorre de forma mais lenta e duradoura ocorrendo concomitante recrutamento e saída de leucócitos do sistema vascular, sem que ocorra, portanto, leucopenia.

0 desenvolvimento de hiperglicemia no tempo 36 horas corrobora os achados de um estudo anterior, onde foram observados elevações nos níveis de glicose e insulina no mesmo período (Van Eps \& Pollitt 2006). Assim, apesar dos produtos da fermentação servirem como fonte energética após absorvidos, é pouco provável que o aumento da glicemia tenha alguma ligação direta com esse evento, pois a fermentação ocorreu no intestino grosso gerando ácido lático (Moore \& Barton 2003). Por outro lado, tem sido demonstrada uma considerável elevação nos níveis de cortisol precedendo a elevação da glicose no mesmo modelo (Van Eps \& Pollitt 2006). Dessa maneira, é provável que a hiperglicemia transitória observada nesse experimento seja atribuída aos efeitos diabetogênicos do cortisol e não à absorção de ácidos graxos voláteis no intestino grosso seguida de neoglicogênese no fígado (Mackay 1992, Moore \& Barton 2003).

Apesar das alterações clínicas relacionadas à diarreia, não houve concomitante alteração da frequência respiratória e dos níveis de lactato, sugerindo que esse quadro não foi capaz de alterar o equilíbrio ácido-base (Moore \& Barton 2003).

0 aumento da transaminase ALT às 36 horas e da bilirrubina entre 36 e 48 horas são compatíveis com algum grau de lesão hepatocelular. Como não foram observadas diferenças significativas entre os animais tratados e não tratados com ICXCR1/2, sugere-se que as alterações hepáticas foram causadas pela endotoxemia e não por algum tipo de toxicidade da droga. A anorexia exibida por animais febris e a hemoconcentração devido à diarreia podem ter contribuído para a elevação da bilirrubina e ALT (Mackay 1992, Moore \& Barton 2003).

Em conclusão, não foram observadas quaisquer reações adversas clínicas ou hematológicas relacionadas ao uso intravenoso da substância ICXCR1/2, contudo esse fármaco, quando administrado na dose de $30 \mathrm{mg} / \mathrm{kg}$ de peso vivo, 4 vezes ao dia, por 4 aplicações, não foi capaz de prevenir os sinais clínicos de endotoxemia e laminite e as alterações hematológicas características de endotoxemia nos equinos deste estudo.

\section{REFERÊNCIAS}

Ainsworth D.M., Wagner B., Franchini M., Grünig G., Erb H.N. \& Tan J.Y. 2006. Time-dependent alterations in gene expression of interleukin-8 in the bronchial epithelium of horses with recurrent airway obstruction. Am. J. Vet. Res. 67(4):669-677.

Belknap J.K. 2010. Black walnut extract: an inflammatory model. Vet. Clin. North Am., Equine Pract. 26(1):95-101.

Belknap J.K., Giguère S., Pettigrew A., Cochran A.M., Van Eps A.W. \& Pollitt C.C. 2007. Lamellar pro-inflammatory cytokine expression patterns in laminitis at the developmental stage and at the onset of lameness: innate vs. adaptive immune response. Equine Vet J. 39(1):42-47.

Bizzarri C., Beccari A.R., Bertini R., Cavicchia M.R., Giorgini S. \& Allegretti M. 2006. ELR+ CXC chemokines and their receptors (CXC chemokine 
receptor 1 and CXC chemokine receptor 2) as new therapeutic targets. Pharmacol. Ther. 112(1):139-149.

Black S.J., Lunn D.P., Yin C., Hwang M., Lenz S.D. \& Belknap J.K. 2006. Leukocyte emigration in the early stages of laminitis. Vet. Immunol. Immunopathol. 109(1/2):161-166.

Botteon P.T.L., Ferraz V.P., Glória M.B.A., Melo M.M., Paes Leme F.O., Faleiros R.R. \& Alves G.E.S. 2008. Concentrações plasmáticas de triptamina, tiramina e feniletilamina em eqüinos sob efeitos de sobrecarga de carboidratos e antiinflamatórios não esteroidais. Pesq. Vet. Bras. 28:299-302.

Clarke L.L., Garner H.E. \& Hatfield D. 1982. Plasma volume, electrolyte, and endocrine changes during onset of laminitis hypertension in horses. Am. J. Vet. Res. 43:1551-1555.

Coelho F.M., Pinho V., Amaral F.A., Sachs D., Costa V.V., Rodrigues D.H., Vieira A.T., Silva T.A., Souza D.G., Bertini R., Teixeira A.L. \& Teixeira M.M. 2008. The chemokine receptors CXCR1/CXCR2 modulate antigen-induced arthritis by regulating adhesion of neutrophils to the synovial microvasculature. Arthritis Rheum. 58(8):2329-2337.

Faleiros R.R., Macoris D.G., Alves G.E., Souza D.G., Teixeira M.M. \& Moore R.M. 2008. Local and remote lesions in horses subjected to small colon distension and decompression. Can. J. Vet. Res. 72(1):68-76.

Faleiros R.R., Leise B.B., Westerman T., Yin C., Nuovo G.J. \& Belknap J.K. 2009a. In vivo and in vitro evidence of the involvement of CXCL1, a keratinocyte-derived chemokine, in equine laminitis. J. Vet. Intern. Med. 23(5):1086-1096.

Faleiros R.R., Nuovo G.J. \& Belknap J.K. 2009b. Calprotectin in myeloid and epithelial cells of laminae from horses with black walnut extract-induced laminitis. J. Vet. Intern. Med. 23(1):174-181.

Faleiros R.R., Johnson P.J., Nuovo G.J., Messer N.T., Black S.J. \& Belknap J.K. 2011a. Laminar leukocyte accumulation in horses with carbohydrate overload-induced laminitis. J. Vet. Intern. Med. 25(1):107-115.

Faleiros R.R., Leise B.S., Watts M., Johnson P.J., Black S.J. \& Belknap J.K. 2011b. Laminar chemokine mRNA concentrations in horses with carbohydrate overload-induced laminitis. Vet. Immunol. Immunopathol. 144(1/2):45-51.

Fontaine G.L., Belknap J.K., Allen D., Moore J.N. \& Kroll D.L. 2001. Expression of interleukin-1beta in the digital laminae of horses in the prodromal stage of experimentally induced laminitis. Am. J. Vet. Res. 62(5):714-720.

Franchini M., Gill U., von Fellenberg R. \& Bracher V.D. 2000. Interleukin-8 concentration and neutrophil chemotactic activity in bronchoalveolar lavage fluid of horses with chronic obstructive pulmonary disease following exposure to hay. Am. J. Vet. Res. 61(11):1369-1374.

Giustizieri M.L., Mascia F., Frezzolini A., De Pità O., Chinni L.M., Giannetti A., Girolomoni G. \& Pastore S. 2001. Keratinocytes from patients with atopic dermatitis and psoriasis show a distinct chemokine production profile in response to T cell-derived cytokines. J. Allergy Clin. Immunol. 107(5):871-877.

Gorio A., Madaschi L., Zadra G., Marfia G., Cavalieri B., Bertini R. \& Di Giulio A.M. 2007. Reparixin, an inhibitor of CXCR2 function, attenuates inflammatory responses and promotes recovery of function after traumatic lesion to the spinal cord. J. Pharmacol. Exp. Ther. 322(3):973-981.

Hurley D.J., Parks R.J., Reber A.J., Donovan D.C., Okinaga T., Vandenplas M.L., Peroni J.F. \& Moore J.N. 2006. Dynamic changes in circulating leukocytes during the induction of equine laminitis with black walnut extract. Vet. Immunol. Immunopathol. 110(3/4):195-206.

Kim H.Y., Choi J.H., Kang Y.J., Park S.Y., Choi H.C. \& Kim H.S. 2011. Reparixin, an inhibitor of CXCR1 and CXCR2 receptor activation, attenuates blood pressure and hypertension-related mediators expression in spontaneously hypertensive rats. Biol. Pharm. Bull. 34(1):120-127.

Loftus J.P., Belknap J.K., Stankiewicz K.M. \& Black S.J. 2007a. Laminar xanthine oxidase, superoxide dismutase and catalase activities in the prodromal stage of black-walnut induced equine laminitis. Equine Vet. J. 39(1):48-53.
Loftus J.P., Black S.J., Pettigrew A., Abrahamsen E.J. \& Belknap J.K. 2007b. Early laminar events involving endothelial activation in horses with black walnut- induced laminitis. Am. J. Vet. Res. 68(11):1205-1211.

Lunn D.P. \& Hurley D.J. 2009. The role of leukocyte biology in laminitis. Vet. Immunol. Immunopathol. 129(3/4):158-160.

MaCkay R.J. 1992. Endotoxemia, p.225-232. In: Robinson N.E. (Ed.), Current Therapy in Equine Medicine. $3^{\text {rd }}$ ed. W.B. Saunders, Philadelphia.

Marsh D.R. \& Flemming J.M. 2011. Inhibition of CXCR1 and CXCR2 chemokine receptors attenuates acute inflammation, preserves gray matter and diminishes autonomic dysreflexia after spinal cord injury. Spinal Cord 49(3):337-344.

Milinovich G.J., Trott D.J., Burrell P.C., Van Eps A.W., Thoefner M.B., Blackall L.L., Al Jassim R.A., Morton J.M. \& Pollitt C.C. 2006. Changes in equine hindgut bacterial populations during oligofructose-induced laminitis. Environ. Microbiol. 8(5):885-898.

Milinovich G.J., Klieve A.V., Pollitt C.C. \& Trott D.J. 2010. Microbial events in the hindgut during carbohydrate-induced equine laminitis. Vet. Clin. North Am., Equine Pract. 26(1):79-94.

Moore J.N. \& Barton M.H. 2003. Treatment of endotoxemia. Vet. Clin. North Am., Equine Pract. 19(3):681-95.

Moore J.N., Garner H.E. \& Coffman J.R. 1981. Haematological changes during development of acute laminitis hypertension. Equine Vet. J. 13:240242.

Mukaida N. 2003. Pathophysiological roles of interleukin-8/CXCL8 in pulmonary diseases. Am. J. Physiol. Lung Cell Mol. Physiol. 284:566577.

Neuder L.E., Keener J.M., Eckert R.E., Trujillo J.C. \& Jones S.L. 2009. Role of p38 MAPK in LPS induced pro-inflammatory cytokine and chemokine gene expression in equine leukocytes. Vet. Immunol. Immunopathol. 129(3/4):192-199.

Nieto J.E., MacDonald M.H., Braim A.E. \& Aleman M. 2009. Effect of lipopolysaccharide infusion on gene expression of inflammatory cytokines in normal horses in vivo. Equine Vet. J. 41(7):717-719.

Pollitt C.C. 2007. Laminitis theory: shots around the target. Conferência Anual da ABRAVEQ, São Paulo. 15p. Disponível em <www.abraveq.com. br> Acesso em 4 dez. 2012.

Souza D.G., Bertini R., Vieira A.T., Cunha F.Q., Poole S., Allegretti M., Colotta F. \& Teixeira M.M. 2004. Repertaxin, a novel inhibitor of rat CXCR2 function, inhibits inflammatory responses that follow intestinal ischaemia and reperfusion injury. Brit. J. Pharmacol. 143(1):132-142.

Stewart A.J., Pettigrew A., Cochran A.M. \& Belknap J.K. 2009. Indices of inflammation in the lung and liver in the early stages of the black walnut extract model of equine laminitis. Vet. Immunol. Immunopathol. 129(3/4):254-260.

Van Eps A.W. \& Pollitt C.C. 2006. Equine laminitis induced with oligofructose. Equine Vet. J. 38(3):203-208.

Van Eps A.W., Leise B.S., Watts M., Pollitt C.C. \& Belknap J.K. 2012. Digital hypothermia inhibits early lamellar inflammatory signalling in the oligofructose laminitis model. Equine Vet J. 44(2):230-237.

Visser M.B. \& Pollitt C.C. 2011. Lamellar leukocyte infiltration and involvement of IL-6 during oligofructose-induced equine laminitis development. Vet. Immunol. Immunopathol. 144(1/2):120-128.

Visser M.B. \& Pollitt C.C. 2012. The timeline of metalloprotease events during oligofructose induced equine laminitis development. Equine Vet. J. 44(1):88-93.

Woodman L., Sutcliffe A., Kaur D., Berry M., Bradding P., Pavord I.D. \& Brightling C.E. 2006. Chemokine concentrations and mast cell chemotactic activity in BAL fluid in patients with eosinophilic bronchitis and asthma, and in normal control subjects. Chest 130(2):371-378.

Zarbock A., Allegretti M. \& Ley K. 2008. Therapeutic inhibition of CXCR2 by Reparixin attenuates acute lung injury in mice. Brity. J. Pharmacol. 155(3):357-364. 